\title{
Morfoanatomia da plântula e comparação da folha nas fases juvenis e adulta de Piptocarpha angustifolia (Asteraceae)
}

Seedling morpho-anatomy and comparison between eophylls and nomophylls of Piptocarpha angustifolia (Asteraceae)

\author{
Betina Kellermann ${ }^{1}$, Cleusa Bona ${ }^{1,3}$ \& Luiz Antonio de Souza ${ }^{2}$
}

\begin{abstract}
Resumo
Morfoanatomia da plântula e comparação da folha nas fases juvenis e adulta de Piptocarpha angustifolia (Asteraceae). O estudo morfológico nas primeiras fases de desenvolvimento permite a observação de estruturas transitórias, que desaparecem com a passagem para a fase adulta. O estudo da morfoanatomia da plântula e das fases juvenis e adulta de Piptocarpha angustifolia foi realizado com o objetivo de se levantar características diagnósticas da espécie, principalmente nos estágios iniciais de desenvolvimento. P. angustifolia é espécie arbórea que ocorre exclusivamente na Floresta Ombrófila Mista Montana. As amostras foram coletadas e fixadas em FAA 50 a partir de plantas cultivadas ( 13 e 35 dias após germinação) e folhas de indivíduos jovens e adultos no campo. Os caracteres como os tipos de germinação (fanerocotiledonar e epígea) e a morfologia foliar permitem o reconhecimento das plântulas e plantas jovens na mata. Os caracteres estruturais que podem auxiliar no reconhecimento da espécie são: região de transição raiz/caule; nó cotiledonar trilacunar; nó unilacunar do eofilo; presença de hidatódios no eofilo; variação do número de feixes vasculares no pecíolo e nervura mediana nos tipos foliares; dorsiventralidade e a variação no formato e número de células do mesofilo dos cotilédones, eofilos e metafilos.
\end{abstract}

Palavras-chave: cotilédone, desenvolvimento pós-seminal, eofilo, metafilo, plântula.

\begin{abstract}
Seedling morphoanatomy and leaf comparison in juvenile and adult stages of Piptocarpha angustifolia (Asteraceae). Morphology studies of the first development stages of plants allow the observation of transitory structures that disappear when they become mature. The aim of this study is to analyse the morphological and anatomical aspect of the structure of Piptocarpha angustifolia, in seendling, juvenile and adult stages, in order to get up diagnostic characteristics of the species, especially in the early stages of development. P. Angustifolia is a native arboreous species from Mixed Ombrophylous Mountain Forest. Samples were collected and fixed in FAA 50 from cultivated plants (13 and 35 days after germination) and leaves of juvenile and adults stages in the field. The characters as types of germination (phanerocotylar and epigeal) and leaf morphology allow the recognition of seedlings and saplings in the forest. The structural characters that can aid in the recognition of the species are: the root/stem transition zone; the trilacunar cotyledon node; the unilacunar eophyll node; the presence of hydathodes in eophyll; the variation in the number of vascular bundles in the petiole and midrib checked in leaf types; the variation in shape and number of mesophyll cells of cotyledons, and eophylls metaphylls.
\end{abstract}

Key words: cotyledons, post seminal development, eophyll, metaphyll, seedling.

\section{Introdução}

O estudo da fase inicial do desenvolvimento das plantas tem grande valor para estabelecer a dinâmica de populações de uma floresta e também para o manejo silvícola. Pode servir, ainda, como índice para determinar se uma vegetação se encontra em estado sucessional ou em clímax, de acordo com a diversidade de espécies e de

\footnotetext{
' Universidade Federal do Paraná, Setor de Ciências Biológicas, Depto. Botânica, 81531-990, Curitiba, PR, Brasil.

${ }^{2}$ Universidade Estadual de Maringá, Depto. Biologia, Av. Colombo 5790, Zona 7, 87020-900, Maringá, PR, Brasil.

${ }^{3}$ Autora para correspondência: bonacleusa@gmail.com
} 
indivíduos que ocorrem no solo (Amo 1979), além de permitir a observação de estruturas transitórias, as quais desaparecem com a passagem para a fase adulta (Ricardi et al. 1977).

As cerca de 250 mil espécies de Angiospermae apresentam uma diversidade enorme de tipos morfológicos de sementes e plântulas. Essa diversidade dificulta a identificação taxonômica dos indivíduos jovens devido às diferenças morfológicas em relação aos indivíduos adultos. No geral, a morfoanatomia de plântulas ainda é pouco conhecida (Souza 2009a) e na área florestal, o reconhecimento das espécies arbóreas nativas, na fase juvenil, fica praticamente dependente do conhecimento de mateiros regionais (Rotta 2007). Gogosz et al. (2010), em análise do desenvolvimento de Campomanesia xanthocarpa $\mathrm{O}$. Berg., concluem que as características anatômicas e morfológicas da espécie são úteis para sua identificação em estágio inicial de desenvolvimento. Conclusão semelhante é feita por Mayer et al. (2008) para Rollinea sylvatica (A. St.-Hil.) Mart., cujos caracteres anatômicos seriam úteis para a taxonomia do grupo e para realizar inferências filogenéticas entre os gêneros.

Asteraceae possui uma distribuição cosmopolita, sendo a maior família de eudicotiledôneas, com cerca de 1600 a 1700 gêneros e 24000-30000 espécies (Souza \& Lorenzi 2008). No Brasil, a família está bem representada, com aproximadamente 250 gêneros e 2000 espécies (Souza \& Lorenzi 2008). Sua morfoanatomia é relativamente bem conhecida, principalmente em relação às estruturas secretoras, típicas da família (Metcalfe \& Chalk 1957; Smith 1982; Lersten \& Curtis 1987; Monteiro et al. 1995; Castro et al. 1997; Grokoviski et al. 2009). Segundo Santos et al. (2014) a zona de transição entre a raiz e o caule nas plântulas de Asteraceae são similares. No entanto, os autores indicam que as variações no nível da região de transição raiz/caule, a formação da bainha de cotilédone, endarquia ou tetrarquia e a divisão de cordões de floema, podem ser elementos de importância taxonômica (Santos et al. 2014).

Piptocarpha angustifolia Dusén ex Malme, popularmente conhecida como vassourão-branco, é espécie arbórea característica e exclusiva da Floresta Ombrófila Mista Montana (Floresta com Araucária), na vegetação secundária em estágio inicial arbóreo (Carvalho 2003). Sua madeira é empregada para usos internos na construção civil e na produção de chapas de madeira compensada (Lorenzi 2002). Sob o aspecto ecológico, ela tem utilidade na recomposição de áreas degradadas e se destaca em locais que tenham sofrido acentuada interferência humana pela extração de madeira (Souza \& Lorenzi 2008), sendo uma das melhores indicadores de vegetação semi-devastada do planalto sul-brasileiro (Carvalho 2003).

$\mathrm{O}$ estudo da morfologia e anatomia de Piptocarpha angustifolia foi realizado neste trabalho com o objetivo de caracterizar a espécie, principalmente nos estágios iniciais de desenvolvimento e comparar a folha nas fases juvenis e adulta, para auxiliar no reconhecimento da planta em seu ambiente de ocorrência, e fornecer dados que possam contribuir com estudos ecológicos e taxonômicos.

\section{Material e Métodos}

O trabalho foi desenvolvido a partir de germinação em laboratório e coleta a campo. Para germinação foram utilizadas sementes provenientes do Laboratório de Sementes da Embrapa Florestas (coletados no município de Colombo - Paraná, região de Floresta Ombrófila Mista, em outubro de 2009). A coleta a campo, das amostras de indivíduos jovens (dois anos de idade, (Kellermann 2011) e adultos (em fase reprodutiva), foi realizada na Reserva Florestal Embrapa/Epagri, Caçador, Santa Catarina. As sementes foram mensuradas quanto ao tamanho (largura e comprimento) e o peso calculando-se a média de 100 unidades. A germinação foi feita em bandejas plásticas com vermiculita e as amostras foram coletadas na fase de plântula (13 dias, fase desde a germinação consumada da semente até a formação da primeira folha ou eofilo), e a fase sequente, planta jovem (35 dias, que se estende até a formação da primeira folha definitiva, o metafilo (Souza 2009a, b). No caso de P. angustifolia, a fase jovem pode se estender por vários anos, com a emissão de sucessivos eofilos antes da emissão da folha adulta (metafilo).

Amostras de raiz (região de ramificação), hipocótilo, cotilédones, epicótilo e eofilo foram coletados de espécimes cultivados, e eofilo e metafilos de indivíduos jovens e adultos em campo. A fixação foi feita em FAA 50 e as amostras armazenadas em etanol 70\% (Johansen 1940). Na plântula foram feitas secções seriadas do ápice da raiz primária ao epicótilo e no terço médio do limbo e pecíolo das folhas. Nas plantas jovens e adultas foram analisados os eofilos e metafilos completamente desenvolvidos (a partir do quarto 
nó). Parte das amostras foi seccionada à mão livre, nos planos transversal e longitudinal sendo as secções coradas com safranina e azul de astra (Bukatsch 1972) e montadas em lâminas semipermanentes. Para montagem de lâminas permanentes as amostras foram desidratadas em série etílica e incluídas em historresina Leica, conforme orientações do fabricante, e secionadas transversalmente em micrótomo de rotação. Essas secções foram coradas com azul de toluidina (O’Brien et al. 1964) e montadas em resina sintética. Foram realizados testes histoquímicos, em secções a mão livre montadas em lâminas semipermanentes, para detecção de lipídeos (Sudan III) (Sass 1951), para amido (lugol) e para compostos fenólicos (cloreto férrico) (Johansen 1940).

As superfícies adaxial e abaxial dos cotilédones e eofilos foram investigadas sob microscopia eletrônica de varredura (MEV). A análise das folhas foi realizada em amostras previamente fixadas em FAA 50, desidratadas em série etílica e submetidas a secagem ao ponto crítico em $\mathrm{CO}_{2}$ (Balzers CPC 10). Estas amostras foram fixadas em suporte metálico com fita adesiva de cobre e metalizadas com ouro (30 a $40 \mathrm{~nm}$ ) (Balzers Sputtering SCD 030). As eletromicrografias foram obtidas em Microscópio Eletrônico de Varredura JEOL JSM - 6360LV.

A descrição do padrão de nervação das folhas seguiu Hickey (1973) e a classificação adotada das plântulas foi a de Vogel (1980) e Garwood (1995). As fases de desenvolvimento foram ilustradas mediante desenhos e/ou fotografias digitais obtidas com câmera manual. As fotomicrografias foram obtidas por captura de imagem com câmera digital (Sony Cyber Shot 7.2) acoplada ao microscópio.

Para avaliar as diferenças morfológicas das folhas de indivíduos jovens (sub-bosque) e adultos (dossel) em campo foram feitas mensurações da intensidade luminosa e da área foliar dos eofilos e metafilos. Para tanto, foram coletadas 10 folhas entre o quarto e sexto nós, no sentido ápice-base, de cinco indivíduos jovens e cinco adultos. A área foliar foi calculada a partir da imagem digitalizada em scanner utilizando o programa Image (versão 1.46r, National Institute of Health, USA). A análise de variância (ANOVA) foi utilizada para calcular as médias das áreas foliares através do programa estatístico PAST (2.16, University of Oslo), com nível de $5 \%$ de probabilidade. A intensidade luminosa foi medida com luxímetro digital (ICEL Manaus, LD-550), resultando em $100 \%$ em sol pleno, $92,21 \%$ no dossel e $27,7 \%$ no sub-bosque.

\section{Resultados}

Morfologia

A semente é alongada e de cor amarela, com tamanho médio de $3,3 \mathrm{~mm}$ (desvio padrão 0,025 ) de comprimento por $0,65 \mathrm{~mm}$ (desvio padrão 0,018$)$ de largura e peso médio de 0,06432 g (desvio padrão 0,000832). A plântula é epígea e fanerocotiledonar (Fig. 1a-c) e a germinação teve início 15 dias após a semeadura com a protrusão do eixo hipocótilo-radicular (Fig. 1a). O desenvolvimento da raiz e do hipocótilo é relativamente rápido e o coleto não é morfologicamente visível. A plântula com quatro dias de idade apresenta hipocótilo alongado e verde, raiz primária sem ramificações e cotilédones completamente expandidos (Fig. 1c). As ramificações da raiz ocorrem nas plantas jovens com idade aproximada de 20 dias (Fig. 1e). Os cotilédones são foliáceos, delgados e fotossintetizantes (Fig. 1c). Os entrenós, incluindo o epicótilo, são muito reduzidos nas fases de plântula e planta jovem, o que dificulta a identificação do tipo de filotaxia, mas que é alterna helicoidal. $\mathrm{O}$ epicótilo é visível quando a planta apresenta 35 dias de idade (Fig. 1f). O estágio inicial da fase de planta jovem é caracterizado a partir do $13^{\circ}$ dia, quando se observa o segundo eofilo expandido (Fig. 1e).

Os cotilédones foliáceos (Fig. 1c-f) possuem cerca de $0,5 \mathrm{~cm}$ de comprimento, formato obovado, ápice retuso, base ligeiramente decurrente, margem inteira, venação do tipo camptódromo broquidódromo (Fig. 1g) e filotaxia oposta (Fig. 1f).

Os vários eofilos nas fases iniciais de desenvolvimento (Fig. 1d-f) são semelhantes morfologicamente, caracterizando-se como folhas simples, alternas, de formato elíptico, base decurrente, ápice obtuso e margem levemente serrada (Fig. 1f,h). A nervação é do tipo camptódromo semicraspedódromo (Fig. 1h). No entanto, em plantas na fase juvenil, os eofilos apresentam formato lanceolado, ápice agudo e margem serrada (Fig. 1i).

Os metafilos são simples, alternos, de formato lanceolado, base cuneada, ápice agudo, margem levemente serrada e nervação craspedódroma (Fig. 1j). Plantas juvenis em campo apresentaram área foliar média de 3822,5 $\mathrm{mm}^{2}$ para os eofilos e $409,76 \mathrm{~mm}^{2}$ para os metafilos. A análise de variância indicou uma diferença significativa no tamanho entre o eofilo e metafilos coletados em campo ( $p=3,942 \mathrm{E}-50)$. 

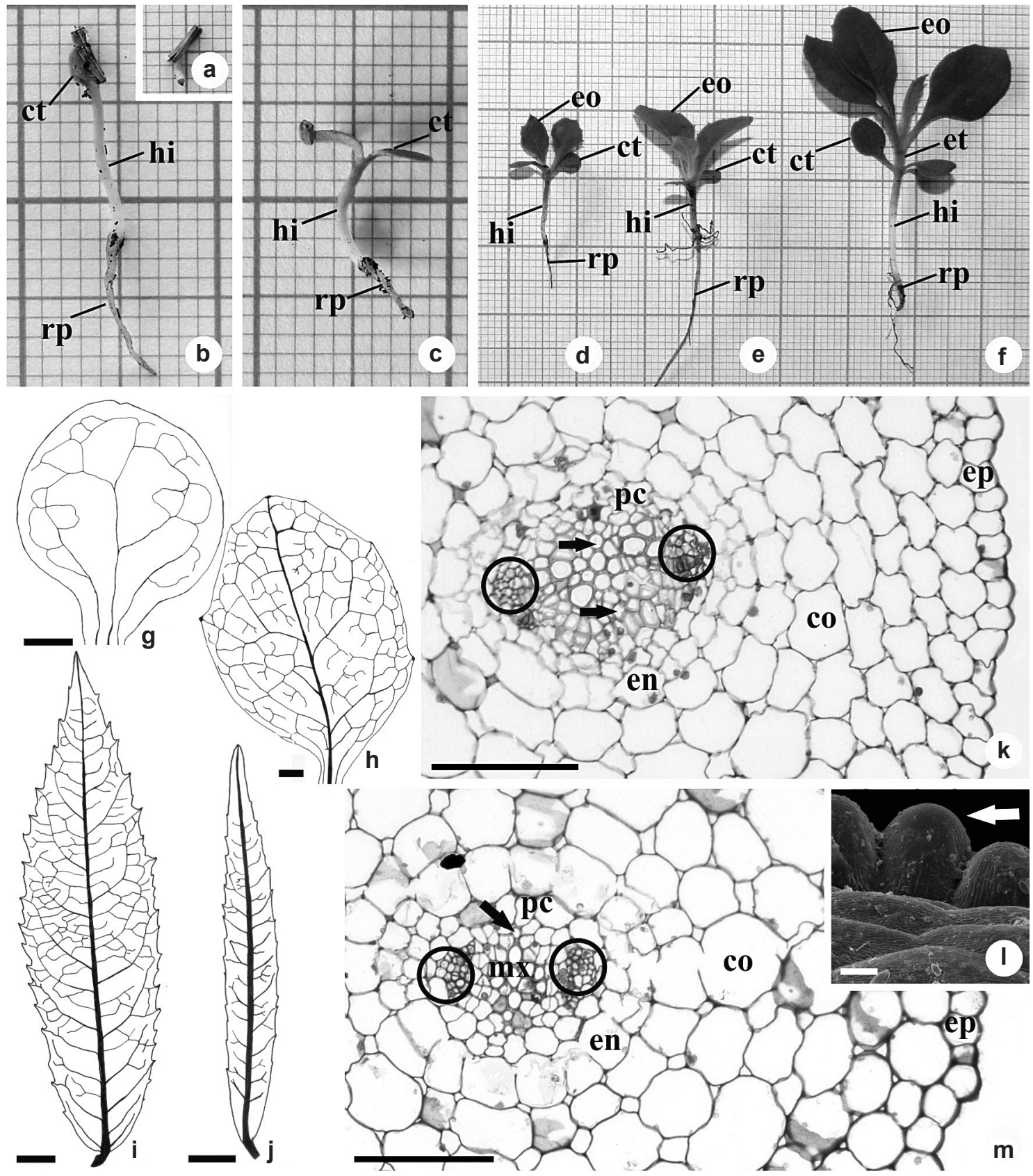

Figura 1 - Piptocarpha angustifolia Dusén ex Malme - a-f. etapas da germinação - a. plântula com um dia; b. plântula com três dias; c. plântula com quatro dias; d. plântula com 13 dias; e. planta jovem com 20 dias; f. planta jovem com 35 dias; g. cotilédone; h. eofilo da plântula; i. eofilo da planta jovem com aproximadamente quatro anos; j. metafilo de indivíduo adulto; $\mathrm{k}$. raiz diarca de plântula, 13 dias após a germinação; 1. detalhe das papilas (seta branca) e cutícula estriada do hipocótilo (MEV); m. secção transversal do hipocótilo na porção mediana, 13 dias após a germinação. (co: córtex; ct: cotilédone; en: endoderme; ep: epiderme; eo: eofilo; et: epicótilo; hi: hipocótilo; mx: metaxilema; pc: periciclo; rp: raiz principal; círculo: floema; seta preta: protoxilema). Barras: $1=20 \mu \mathrm{m} ; \mathrm{k}, \mathrm{m}=100 \mu \mathrm{m} ; \mathrm{g}, \mathrm{h}=1 \mathrm{~mm} ; \mathrm{i}, \mathrm{j}=1 \mathrm{~cm}$.

Figure 1 - Piptocarpha angustifolia Dusén ex Malme - a-f. stages of germination - a. seedling with one day old; b. seedling with three days old; c. seedling with four days old; d. seedling with 13 days old; e. young plant with 20 days old; f. young plant with 35 days old; g. cotyledon; h. seedling eophyll; i. eophyll from the young plant in about four years old; j. the adult metaphyll; $\mathrm{k}$. seedling diarch root, 13 days after germination; 1. detail of the hypocotyl with papillae (white arrow) and striated cuticle (SEM); m. cross section of hypocotyl in the midlle portion, 13 days after germination. (co: cortex; ct: cotyledon; en: endoderm; ep: epidermis; eo: eophyll; et: epicotyl; hi: hypocotyl; mx: metaxylem; pc: pericycle; rp: root; circle: phloem; black arrow: protoxylem). Bars: $1=20 \mu \mathrm{m} ; \mathrm{k}, \mathrm{m}=100 \mu \mathrm{m} ; \mathrm{g}, \mathrm{h}=1 \mathrm{~mm} ; \mathrm{i}, \mathrm{j}=1 \mathrm{~cm}$. 


\section{Anatomia}

Em secção transversal, a raiz apresenta epiderme uniestratificada com tricomas unicelulares. $\mathrm{O}$ córtex é parenquimático (Fig. 1k), com a endoderme provida de paredes delgadas e estrias de Caspary (reação positiva com Sudan III). O cilindro vascular apresenta periciclo parenquimático uniestratificado, dois cordões floemáticos e xilema com dois polos protoxilemáticos, caracterizando a raiz como diarca (Fig. 1k). A instalação do câmbio ocorre na região proximal da raiz, ainda na fase de plântula. $\mathrm{O}$ crescimento secundário é bem caracterizado na planta jovem.

O hipocótilo tem epiderme uniestratificada, estomatífera, com fileiras de células papilosas alternadas com células não papilosas (Fig. 11-m). A cutícula apresenta leve estriação epicuticular (Fig. 11). No córtex ocorre endoderme com estrias de Caspary e grãos de amido (reação positiva para lugol). A vascularização do hipocótilo na plântula é feita por dois cordões floemáticos e xilemáticos primários alternos, em que a condição exarca do xilema se mantém em quase toda a sua extensão (Fig. 1m). A condição endarca, tipicamente caulinar, surge apenas na região distal do hipocótilo, nas proximidades do nó cotiledonar. No hipocótilo da planta com 35 dias de idade observa-se crescimento secundário em que o câmbio tem origem semelhante ao da raiz, ou seja, procambial e pericíclica.

$\mathrm{Na}$ região do nó cotiledonar, os tecidos vasculares provenientes do hipocótilo apresentam dois traços foliares de maior calibre (Fig. 2a,b, seta preta), que se dirigem um para cada cotilédone (Fig. 2c, seta preta), e dois outros traços de menor calibre (Fig. 2a,b, seta branca), que se bifurcam e direcionam um para cada cotilédone (Fig. 2a-c, seta branca). Assim, o nó cotiledonar caracteriza-se como trilacunar, ressaltando-se que há um traço independente para cada cotilédone e dois traços comuns. Nessa região também se organizam os feixes epicotiledonares que se localizam na porção central, envolvendo a medula parenquimática (Fig. 2b).

$\mathrm{O}$ epicótilo possui menor diâmetro que o hipocótilo, é recoberto por tricomas tectores estrelados (Fig. 2d) e glandulares (Fig. 2e) e epiderme uniestratificada (Fig. 2f). O tricoma tector possui pedúnculo unisseriado e uma célula terminal ramificada. Os tricomas glandulares possuem pedúnculo bisseriado pluricelular, cabeça glandular arredondada bicelular, apresentando cutícula distendida no ápice (por acúmulo de material secretado) e são proeminentes na superfície. $O$ córtex possui uma ou duas camadas de colênquima subepidérmico e parênquima com poucos cloroplastos (Fig. 2f-g). A endoderme é visível especialmente pela presença de grãos de amido (reação positiva com lugol). O cilindro central tem estrutura eustélica com vários feixes vasculares colaterais distribuídos ao redor da medula parenquimática (Fig. 2f-g). Na planta com 35 dias observa-se crescimento secundário incipiente, com câmbio fascicular já instalado e o interfascicular em início de formação (Fig. $2 \mathrm{~g}$ ).

O nó do eofilo também apresenta três traços, mas com uma lacuna, sendo um traço central de maior calibre (Fig. 2h-i, seta preta) e dois laterais menores (Fig. 2h-i, setas brancas). Os dois traços de menor calibre, diferentemente dos cotilédones, são independentes.

O cotilédone possui epiderme uniestratificada, com células de formato irregular e com paredes anticlinais sinuosas em vista frontal (Fig. 3a-d). Os estômatos são anomocíticos (Fig. 3b) e ocorrem em ambas as faces (Fig. 3c-d), sendo mais numerosos na superfície abaxial, e tricomas glandulares em depressão. O mesofilo é dorsiventral, com parênquima clorofiliano paliçádico é pouco diferenciado, constituído por uma camada de células com formato de cone invertido (Fig. 3c). $\mathrm{O}$ parênquima clorofiliano esponjoso possui de duas a quatro camadas de células, com espaços intercelulares conspícuos (Fig. 3c). A nervura mediana é levemente proeminente na face abaxial e possui um feixe vascular colateral (Fig. 3d). O parênquima clorofiliano é contínuo na região da nervura mediana (Fig. 3d) e bordo.

A epiderme do limbo do eofilo da plântula é uniestratificada, estomatífera e tricomatosa. Em vista frontal, as células epidérmicas têm formato irregular e paredes anticlinais sinuosas (Fig. 3e). Os estômatos são anomocíticos (Fig. 3e) e ocorrem em ambas as faces. Os tricomas tectores e glandulares, semelhantes aos do epicótilo, também estão presentes em ambas as superfícies (Fig. 3f-g). Os tricomas glandulares se encontram inseridos em suave depressão (Fig. 3h-i). O mesofilo é dorsiventral, semelhante ao do cotilédone, composto por uma única camada de parênquima clorofiliano paliçádico e duas a quatro camadas de parênquima clorofiliano esponjoso (Fig. 3j), contínuos na região da nervura mediana (Fig. $3 \mathrm{k}$ ). Os eofilos apresentam hidatódios (Fig. 31-m) no bordo do limbo, caracterizando-se por serem proeminentes, cônicos, revestidos por epiderme 

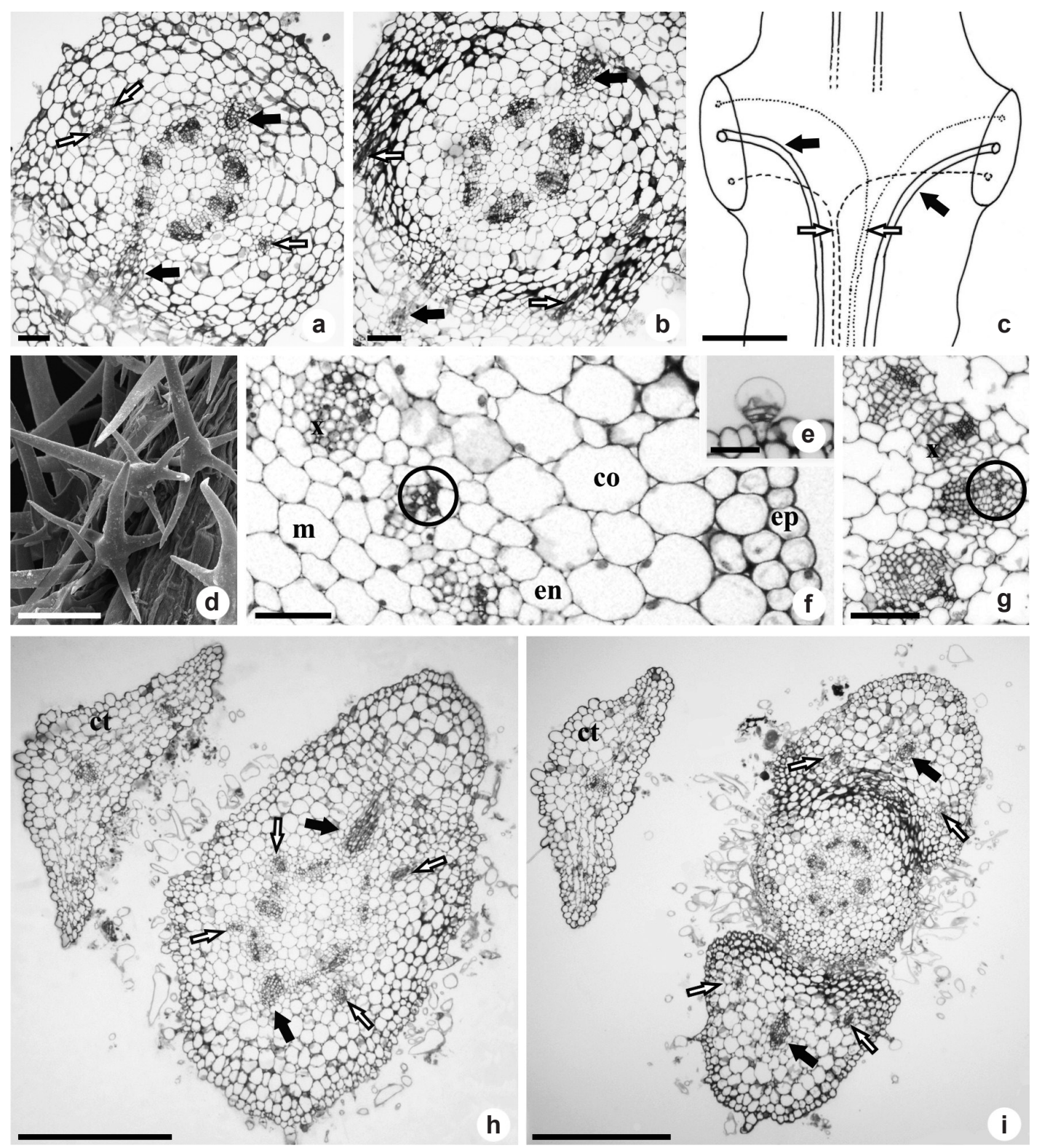

Figura 2 - Piptocarpha angustifolia Dusén ex Malme - a. secção transversal do nó cotiledonar evidenciando traço cotiledonar independente e de maior calibre (seta preta), traços cotiledonares comuns e bifurcados (setas brancas) e feixes epicotiledonares circundando a medula; b. secção transversal acima da anterior evidenciando os feixes cotiledonares comuns (setas brancas) e traços independentes (seta preta) na base do pecíolo; c. esquema da região do nó cotiledonar em vista longitudinal evidenciando os traços independente (linha contínua) e os traços comuns (linha descontínua e pontilhado); d. vista frontal do epicótilo (MEV) evidenciando tricomas tectores estrelados; e. tricoma glandular no epicótilo; f. secção transversal do epicótilo da plântula, 13 dias após germinação; g. secção transversal do epicótilo da planta jovem, 35 dias após germinação; h. secção transversal do nó eofilar evidenciando traços independente de maior calibre (setas pretas) e de menor calibre (setas brancas) e feixes epicotiledonares ao redor da medula; i. epicótilo e as bases dos pecíolos dos eofilos. (co: córtex; ct: cotilédone; en: endoderme; ep: epiderme; m: medula; x: xilema; círculo: floema). Barras: e $=50 \mu \mathrm{m} ; \mathrm{a}, \mathrm{b}, \mathrm{d}, \mathrm{f}, \mathrm{g}=100 \mu \mathrm{m} ; \mathrm{c}=250 \mu \mathrm{m} ; \mathrm{h}, \mathrm{i}=500 \mu \mathrm{m}$.

Figure 2 - Piptocarpha angustifolia Dusén ex Malme - a. cross section of the cotyledon node showing independet cotyledon trait with larger caliber (black arrow), cotyledon common traits and bifurcated (white arrows) and epicotyledonar bundles surrounding the pith; b. cross section above the previous, showing the cotyledon common bundles (white arrows) and independent traits (black arrow) at the base of the petiole; $c$. scheme of the cotyledon node region in longitudinal view showing the independent trace (solid line) and the common trace (discontinuous and dotted line); $d$. front view of the epico' (black arrows) and smaller traits (white arrows) and epicotyledonar bundles around the pith; i. epicotyl and the bases of eophylls petioles. (co: cortex; ct: cotyledon; en: endoderm; ep: epidermis; m: cord; x: xylem; circle: phloem). Bars: e = $50 \mu \mathrm{m} ; \mathrm{a}, \mathrm{b}, \mathrm{d}, \mathrm{f}, \mathrm{g}=100 \mu \mathrm{m} ; \mathrm{c}=250 \mu \mathrm{m} ; \mathrm{h}, \mathrm{i}=500 \mu \mathrm{m}$. 

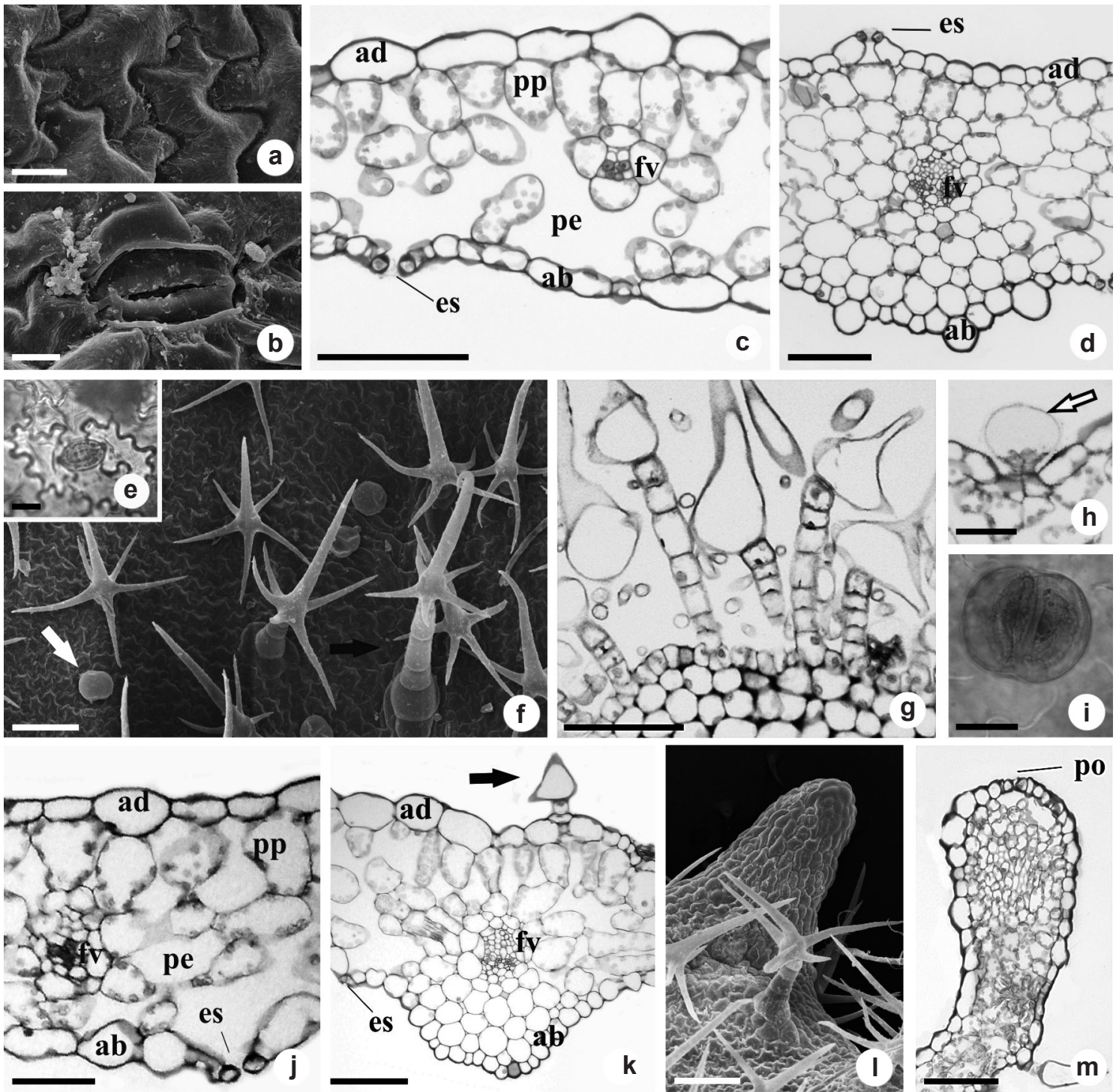

Figura 3 - Piptocarpha angustifolia Dusén ex Malme - a. face adaxial epidérmica do cotilédone (MEV); b. face adaxial epidérmica do cotilédone, com estômato (MEV); c. secção transversal do limbo cotiledonar; d. secção transversal da nervura mediana do cotilédone; e-f. eofilo - e. detalhe da epiderme da face abaxial com estômato anomocítico; f. face adaxial evidenciando tricomas tectores e glandulares (seta branca) (MEV); g. secção transversal do eofilo evidenciando os tricomas tectores com pedúnculo pluricelular; h. tricoma glandular, no eofilo, com cutícula evidente (seta); i. vista frontal do tricoma glandular, no eofilo, evidenciando "cabeça” bicelular; j. secção transversal do eofilo; k. secção transversal da região da nervura mediana do eofilo; $1-\mathrm{m}$. hidatódio no bordo do eofilo - 1. em MEV; m. em secção longitudinal. (ab: epiderme na face abaxial; ad: epiderme na face adaxial; es: estômato; fv: feixe vascular; pe: parênquima esponjoso; pp: parênquima paliçádico; po: poro; seta preta: tricoma tector). Barras: $\mathrm{a}=20 \mu \mathrm{m} ; \mathrm{b}=10 \mu \mathrm{m} ; \mathrm{h}, \mathrm{i}=25 \mu \mathrm{m} ; \mathrm{e}, \mathrm{j}=50 \mu \mathrm{m} ; \mathrm{c}, \mathrm{d}, \mathrm{f}, \mathrm{g}, \mathrm{k}, 1, \mathrm{~m}=100 \mu \mathrm{m}$. Figure 3 - Piptocarpha angustifolia Dusén ex Malme - a. epidermal adaxial side of the cotyledon (SEM); b. epidermal adaxial side of the cotyledon with stomata (SEM); c. cross section of the cotyledon blade; d. cross section of the cotyledon blade midrib; e-f. eophyll - e. detail of epidermis in the adaxial side with anomocytic stomata; f. adaxial side showing tector and gladular trichomes (white arrow) (SEM); g. cross section of eophyll showing the multicellular nonglandular trichomes; $h$. glandular trichome in eophyll with clear cuticle (arrow); i. front view of glandular trichome in eophyll, showing two-cell "head"; j. cross section of eophyll; k. cross section of the eophyll midrib region; l-m. margin of the eophyll with hydathode - 1 . SEM; $m$. longitudinal section. (ab: epidermis in the abaxial side; ad: epidermis in the adaxial side; es: stomata; fv: vascular bundle; pe: spongy parenchyma; pp: palisade parenchyma; po: pore; black arrow: non-glandular trichome). Bars: $a=20 \mu \mathrm{m} ; \mathrm{b}=$ $10 \mu \mathrm{m} ; \mathrm{h}, \mathrm{i}=25 \mu \mathrm{m} ; \mathrm{e}, \mathrm{j}=50 \mu \mathrm{m} ; \mathrm{c}, \mathrm{d}, \mathrm{f}, \mathrm{g}, \mathrm{k}, 1, \mathrm{~m}=100 \mu \mathrm{m}$. 
unisseriada com poros na extremidade, parênquima frouxo e terminação vascular xilemática.

A epiderme do limbo do eofilo da planta jovem é semelhante ao do eofilo da plântula e do cotilédone, sendo uniestratificada, estomatífera e tricomatosa (Fig. 4a-b). Os tricomas tectores e glandulares também estão presentes em ambas as superfícies. O mesofilo também é dorsiventral, como descrito acima, no entanto as células do parênquima paliçádico são mais alongadas e os
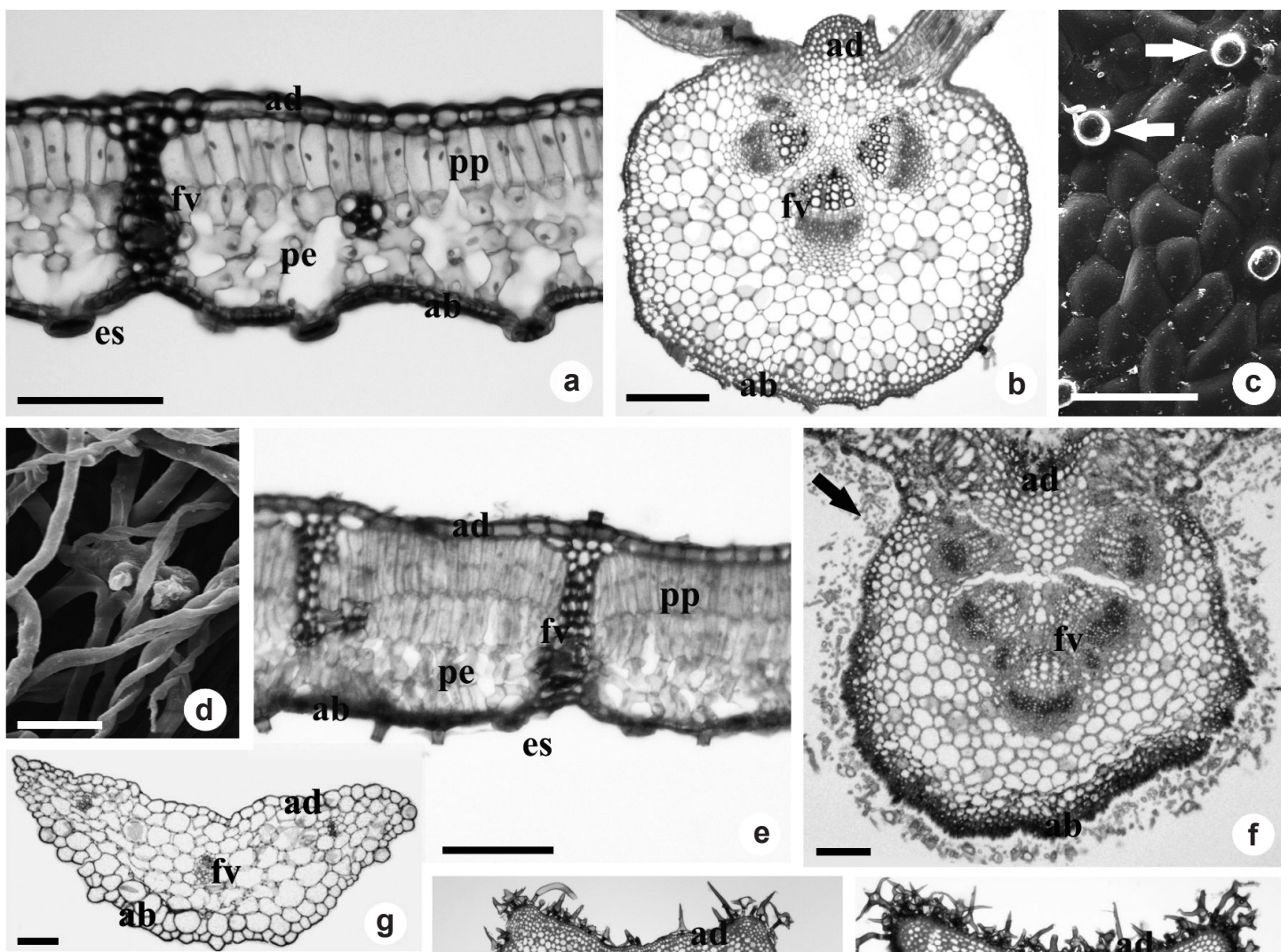

es
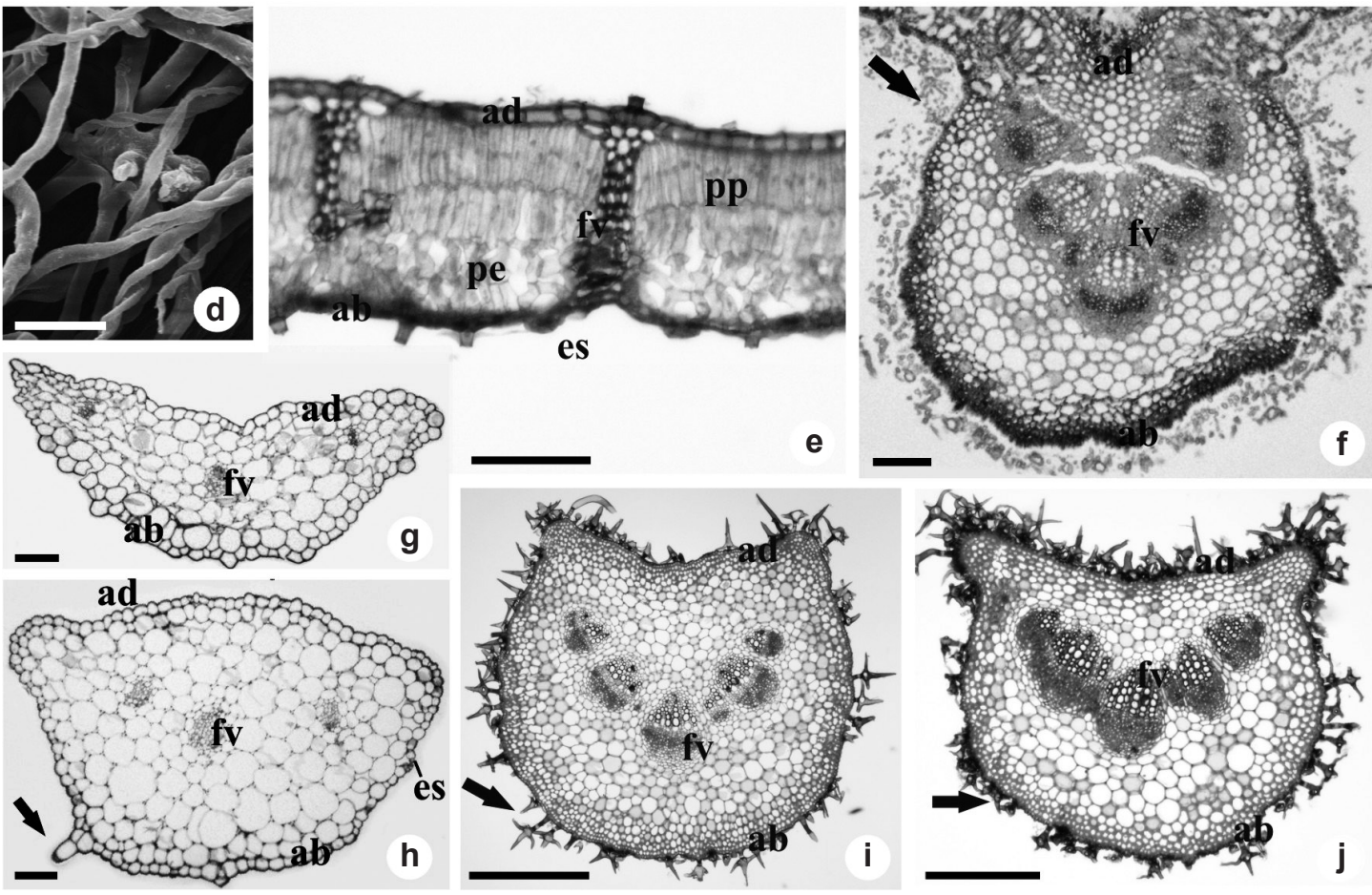

Figura 4 - Piptocarpha angustifolia Dusén ex Malme - a. secção transversal do eofilo da planta jovem; b. secção transversal da nervura mediana do eofilo; c. vista frontal da face adaxial do metafilo evidenciando bases de tricomas tectores (seta branca) (MEV); d. metafilo em vista frontal, face abaxial com tricoma tector estrelado com extremidades alongadas (MEV); e. secção transversal do metafilo; f. secção transversal da nervura mediana do metafilo; g. secção transversal do pecíolo do cotilédone; h. secção transversal do pecíolo do eofilo da plântula; i. secção transversal do pecíolo do eofilo da planta jovem; j. secção transversal do pecíolo do metafilo. (ab: epiderme da face abaxial; ad: epiderme da face adaxial; es: estômato; fv: feixe vascular; pe: parênquima esponjoso; pp: parênquima paliçádico; seta preta: tricoma tector). Barras: $\mathrm{d}=20 \mu \mathrm{m} ; \mathrm{c}=50 \mu \mathrm{m} ; \mathrm{a}, \mathrm{e}, \mathrm{f}, \mathrm{g}, \mathrm{h}=100 \mu \mathrm{m} ; \mathrm{b}=200 \mu \mathrm{m} ; \mathrm{i}, \mathrm{j}=500 \mu \mathrm{m}$. Figure 4 - Piptocarpha angustifolia Dusén ex Malme - a. cross section of eophyll in the young plant; b. Cross section of eophyll midrib; c. front view of metaphyll adaxial side showing bases of non-glandular trichomes (white arrow) (SEM); d. front view of metaphyll, on the abaxial side with branched trichome with long extremities (SEM); e. cross section of metaphyll; f. cross section of metaphyll midrib; g. cross section of cotyledon petiole; h. cross section of eophyll petiole from the seedling; i. cross section of eophyll petiole from the young plant; $j$. cross section of metaphyll petiole. (ab: epidermis in the abaxial side; ad: epidermis in the adaxial side; es: stomato; fv: vascular bundle; pe: spongy parenchyma; pp: palisade parenchyma; black arrow: non-glandular trichome). Bars: $d=20 \mu \mathrm{m} ; \mathrm{c}=50 \mu \mathrm{m} ; \mathrm{a}, \mathrm{e}, \mathrm{f}, \mathrm{g}, \mathrm{h}=100 \mu \mathrm{m} ; \mathrm{b}=200 \mu \mathrm{m} ; \mathrm{i}, \mathrm{j}=500 \mu \mathrm{m}$. 
feixes vasculares possuem extensão da bainha de natureza esclerenquimática (Fig. 4a). A nervura mediana do eofilo da planta jovem possui três feixes vasculares (Fig. 4b).

A epiderme do metafilo na face adaxial (Fig. 4c) apresenta cicatrizes esparsas de tricomas caducos. A epiderme na face abaxial apresenta tricomas glandulares, semelhantes aos descritos anteriormente, e grande quantidade de tricomas tectores estrelados com células terminais filiformes e retorcidas (Fig. 4d). O mesofilo dorsiventral apresenta dois estratos de parênquima clorofiliano paliçádico com células alongadas e dois estratos de parênquima esponjoso (Fig. 4e). A endoderme (bainha do feixe) é de natureza esclerenquimática e se estende em direção a ambas as faces. A nervura mediana do metafilo possui cerca de cinco feixes vasculares dispostos em V (Fig. 4f).

O pecíolo, em secção transversal, tem contorno diferente nas quatro folhas. No cotilédone é lenticular (Fig. 4g); no eofilo da plântula tem contorno mais ou menos trapezoidal (Fig. 4h) com pequenas expansões laterais na porção distal; no eofilo da planta jovem e no metafilo é arredondado na face abaxial e ligeiramente côncavo na face adaxial com reduzidas projeções adaxiais (Fig. 4i-j). A organização dos tecidos é diferente nos quatro tipos foliares. Nota-se epiderme com tricomas esparsos no cotilédone e no eofilo da plântula (Fig. 4g-h) e com alta densidade de tricomas no eofilo da planta jovem e no metafilo (Fig. 4i-j). O tecido fundamental é composto principalmente de parênquima no pecíolo do cotilédone e no eofilo da plântula (Fig. 4g-h) e por várias camadas de colênquima, em posição subepidérmica, seguido por parênquima no eofilo da planta jovem e no metafilo (Fig. 4i-j). Os feixes vasculares são menos desenvolvidos e em número de três no pecíolo do cotilédone e no eofilo da plântula e cerca de cinco nos eofilos das plantas jovens e nos metafilos (Fig. $4 \mathrm{~g}$-j). Além disso, os feixes dispõem-se em meia lua no cotilédone e no eofilo da plântula e em V no eofilo da planta jovem e no metafilo (Fig. 4g-j).

Não foi registrada a presença de compostos fenólicos nos órgãos analisados (teste de cloreto férrico negativo).

\section{Discussão}

As plântulas de Piptocarpha angustifolia se enquadram no tipo PEF (Phanerocotylar, Epigeal, Foliaceus) de Garwood (1995) por apresentarem os cotilédones livres do tegumento seminal, germinação epigeia e cotilédones foliáceos.
Ressel et al. (2004) afirmaram que plântulas do tipo fanero-epígeo-foliáceo apresentam como vantagem, na competição por espaço e luz, a presença de cotilédones fotossintetizantes, o que é característica de espécies de estádios sucessionais iniciais, como é o caso de $P$. angustifolia. Essas características também foram confirmadas nas espécies heliófitas $R$. silvatica e $C$. xanthocarpa por Mayer et al. (2008) e Gogosz et al. (2010), respectivamente. Com referência à classificação de Vogel (1980), as plântulas de P. angustifolia podem se enquadrar no tipo Macaranga, considerado pelo autor como o mais comum entre as plântulas estudadas por ele, sendo registrado em Asteraceae e outras famílias. Este tipo se caracteriza por apresentar basicamente plântulas epigeias e fanerocotiledonares, paracotilédones (cotilédones foliáceos) e as primeiras folhas com filotaxia alterna helicoidal.

Com relação ao tipo de nervação do eofilo, o tipo mais comum em plântulas de eudicotiledôneas estudadas parece ser o broquidódromo. O tipo camptódromo, verificado em $P$. angustifolia, parece ser mais raro e foi registrado em espécies de Clusiaceae (Souza et al. 2009).

Do ponto de vista estrutural, a raiz e grande parte do hipocótilo da espécie em estudo apresentam poucas diferenças entre si, as quais se restringem mais à epiderme e ao córtex. $\mathrm{O}$ hipocótilo apresenta epiderme com cutícula estriada e cloroplastos nas células corticais. A zona de transição raiz-caule é restrita à região próxima ao nó cotiledonar. Esse tipo de zona de transição de $P$. angustifolia pode ser classificado como "alto", proposto por Compton (1912) para plântulas de espécies de Fabaceae (Leguminosae). De acordo com o autor, as mudanças transicionais da condição exarca (raiz) para endarca (caule) não começam até próximo da região apical do hipocótilo e são incompletas no nó cotiledonar. De acordo com Vogel (1980), a zona de transição do hipocótilo, característica de plântulas, pode ser mais longa ou mais curta e até mesmo pode ocupar todo o hipocótilo. Vogel (1980) afirmou, ainda, que esta zona quando restrita a uma pequena área é usualmente encontrada na parte superior do hipocótilo, como verificado em plântulas de $P$. angustifolia.

Com referência, ainda, à região de transição raiz-caule de $P$. angustifolia observa-se que a formação dos três traços cotiledonares no hipocótilo, sendo um independente e dois outros comuns a ambos os cotilédones, não tem registro na literatura, pelo menos em Asteraceae. Souza 
(2009a), que apresenta a estrutura dessa região em várias espécies, pertencentes a diferentes famílias, como Amaranthaceae, Annonacae, Bignoniaceae, Cactaceae, Clusiaceae, Fabaceae (Leguminosae) e Rutaceae, não registra origem semelhante dos traços cotiledonares à observada em $P$. angustifolia. Assim, parece ser comum em espécies de eudicotiledôneas cotilédones com dois traços independentes, não nós cotiledonares trilacunares. Aliás, Bailey (1956), analisando 99 famílias de angiospermas, constatou que $77 \%$ das plântulas têm o mesmo número de cordões vasculares no nó cotiledonar e $60 \%$ dos cotilédones têm duplo traço e nó unilacunar.

O epicótilo da plântula de $P$. angustifolia apresenta os caracteres estruturais de caule descritos para a família por Metcalfe \& Chalk (1957). No epicótilo da espécie em estudo não foram registrados alguns caracteres gerais de Asteraceae, formulados por estes autores, como periciclo esclerenquimático, feixes vasculares corticais e feixes vasculares medulares. É possível que em caules mais velhos de $P$. angustifolia esses caracteres possam estar presentes.

As estruturas secretoras são características da família Asteraceae e têm sido consideradas de valor taxonômico, seja pela diversidade dos tipos, pela posição em que ocorrem ou pela natureza da secreção (Solereder 1908; Lersten \& Curtis 1985; Castro et al. 1997). Das diversas estruturas secretoras encontradas em Asteraceae (Castro et al. 1997), duas foram encontradas em P. angustifolia: tricomas glandulares e hidatódios.

Os tricomas secretores são apêndices epidérmicos, frequentemente localizados em depressões na epiderme, que se distinguem por apresentar células que liberam substâncias de aspecto denso ou hialino; este material pode permanecer dentro do protoplasto destas células, ou então, ser liberado para o espaço subcuticular, que se formou pela distensão da cutícula (Solereder 1908; Castro et al. 1997). Em P. angustifolia os tricomas ocorrem no cotilédone, epicótilo, pecíolo, eofilo e metafilo e não diferem estruturalmente de outras espécies da família já descritas (Monteiro et al. 2001; Lolis \& Milaneze-Gutierre 2003; Aguilera et al. 2004; Melo-de-Pinna 2004; Martins et al. 2006; Appezzato-da-Glória et al. 2008; Grokoviski et al. 2009). A presença de tricomas tectores apenas na face abaxial do metafilo também foi registrada por Grokoviski et al. (2009), e é uma das principais características que delimitam Piptocarpha como um gênero distinto (Smith 1982).
Os hidatódios são responsáveis pelo processo de gutação e são estruturas comuns dentre as Asteraceae (Lersten \& Curtis 1985, 1987; Castro et al. 1997). Melo-de-Pinna (2004) relacionou a presença de hidatódios em duas espécies de Richterago Kuntze, também pertencentes às Asteraceae, com o ambiente encharcado em que vivem. A autora indica que essas estruturas estariam relacionadas ao controle interno de água nas plantas. No caso de $P$. angustifolia, a presença dos hidatódios também pode estar relacionada ao controle interno de água, porém esta espécie não ocorre em ambientes encharcados ou muito úmidos (Carvalho 2003).

A heterofilia é relativamente comum durante o desenvolvimento de uma espécie de eudicotiledônea, principalmente naquela que possui metafilos compostos (Souza et al. 2009). Como já ressaltado, $P$. angustifolia apresenta dimensões e morfologia variáveis entre os cotilédones, os diferentes eofilos e metafilo. Carvalho (2003) também registrou morfologia diferente para folhas de plantas jovens e adultas da mesma espécie. Sob o aspecto estrutural, $P$. angustifolia também apresenta alguns caracteres nos eofilos de planta jovem e metafilos, como grande pubescência e maior número de estratos de parênquima paliçádico, que diferenciam estas folhas dos eofilos e cotilédones das plântulas. É provável que estes caracteres registrados nas folhas de $P$. angustifolia, referentes à área foliar, pilosidade e número de camadas celulares do mesofilo, sejam adaptativos ao fator luminosidade (Jackson 1967; Fahn 1988; Turner 1994; Klich et al. 1997; Marques et al. 2000; Rossato \& Kolb 2010), diferenciando os eofilos, em geral sombreados, e os metafilos expostos à luz de $P$. angustifolia.

Os caracteres como os tipos de germinação (fanerocotiledonar e epígea) e a morfologia foliar de Piptocarpha angustifolia permitem o reconhecimento das plântulas e plantas jovens na mata. Com referência aos caracteres estruturais e ontogenéticos registrados no estudo da espécie e que merecem destaque são: a região de transição raiz/caule; o nó cotiledonar trilacunar; o nó unilacunar do eofilo; a presença de hidatódios no eofilo; a variação do número de feixes vasculares no pecíolo e nervura mediana verificada nos tipos foliares; e a dorsiventralidade dos cotilédones, eofilos e metafilos, mas com variação no formato celular e no número de células do mesofilo. 


\section{Agradecimentos}

Os autores agradecem ao Laboratório de Sementes da Embrapa Florestas, o fornecimento de parte das sementes de P. angustifolia. Ao Centro de Microscopia Eletrônica da UFPR, a utilização do laboratório. E à CAPES e ao CNPq, a concessão de bolsas.

\section{Referências}

Aguilera, D.B.; Meira, R.M.S.A. \& Ferreira, F.A. 2004. Anatomia e Histoquímica dos órgãos vegetativos de Siegesbeckia orientalis (Asteraceae). Planta Daninha 22: 483-489.

Amo, R.S. 1979. Clave para plántulas y estados juveniles de especies primarias de una selva alta perennifolia en Veracruz, Mexico. Biotica 42: 59-108.

Appezzato-da-Glória, B.; Hayashi, A.H.; Cury, G.; Soares, M.K.M. \& Rocha, R. 2008. Occurrence of secretory structures in underground systems of seven Asteraceae species. Botanical Journal of the Linnean Society 157: 789-796.

Bailey, I.W. 1956. Nodal anatomy and vasculature of seedlings. Journal of Arnold Arboretum 37: 269-287.

Bukatsch, F. 1972. Bemerkugen zur doppelfärbung Astrablau-Safranin. Mikrokosmos 14: 255.

Carvalho, P.E.R. 2003. Espécies arbóreas brasileiras. Embrapa Informação Tecnológica / Embrapa Florestas, Brasília / Colombo. 1040p.

Castro, M.M.; Leitão-Filho, H.F. \& Monteiro, W.R. 1997. Utilização de estruturas secretoras na identificação dos gêneros de Asteraceae de uma vegetação de cerrado. Revista Brasileira de Botânica 20: 163-174.

Compton, R.H. 1912. Investigation of the seedling structure in the Leguminosae. The Journal of the Linnean Society 41: 1-122.

Duke, J.A. 1969. On tropical tree seedlings. I. Seeds, seedlings, systems and systematics. Annals of the Missouri Botanical Garden 56: 125-161.

Eames, A.J. 1961. Morphology of the angiosperms. McGraw-Hill Book Company, Oxford. 518p.

Fahn, A. 1988. Secretory tissues in vascular plants. New Phytologist 108: 229-257.

Garwood, N.C. 1995. Functional morphology of tropical tree seedlings. In: M.D. Swaine (ed.). The ecology of tropical forest tree seedlings. Vol. 17. The Parthenon Publishing Group, Paris. Pp. 59-129.

Gogosz, A.M.; Cosmo, N.L.; Bona, C.B. \& Souza. L.A. 2010. Morfoanatomia da plântula de Campomanesia xanthocarpa O. Berg. (Myrtaceae). Acta Botanica Brasilica 24: 613-623.

Grokoviski, L.; Cervi, A.C. \& Tardivo, R.C. 2009. O gênero Piptocarpha R.Br. (Asteraceae: Vernonieae) no Estado do Paraná, Brasil. Acta Botanica Brasilica 23: 486-498.
Hickey, L.J. 1973. A revised classification of the architecture of dicotyledons leaves. American Journal of Botany 60: 17-33.

Jackson, L.W.R. 1967. Relation of leaf structure to chade tolerance of dicotyledonous tree species. Forest Science 13: 321-323.

Johansen, D.A. 1940. Plant microtechnique. McGraw-Hill Book Company, New York. 523p.

Kellermann, B. 2011. Monitoramento da regeneração natural em fragmento de Floresta Ombrófila Mista e morfoanatomia de plântulas e tirodendros de Piptocarpha angustifolia Dusén ex Malme (Asteraceae). Mestrado em Botânica. Universidade Federal do Paraná, Curitiba. 140p.

Klich, M.G.; Brevedan, R.E. \& Villamil, S.C. 1997. Leaf anatomy and ultrastructure of Poa ligurais after defoliation and water stress. Proceedings of the $18^{\text {th }}$ International Grassland Congress 1: 37-38.

Lersten, N.R. \& Curtis, J.D. 1985. Distribution and anatomy of hidathodes in Asteraceae. Botanical Gazette 146: 106-114.

Lersten, N.R. \& Curtis, J.D. 1987. Internal secretory spaces in Asteraceae. A review and original observations on Conyza canadensis (tribe Astereae). La Cellule 74: 179-196.

Lolis, M.I.G.A. \& Milaneze-Gutierre, M.A. 2003. Morfoantomia das folhas de Vernonia condensate Baker (Asteraceae), o "figatil". Revista Brasileira de Farmacognosia 13: 68-71.

Lorenzi, H. 2002. Árvores brasileiras: manual de identificação e cultivo de plantas arbóreas nativas do Brasil. Instituto Plantarum de Estudos da Flora, Nova Odessa. 368p.

Marques, A.R.; Garcia, Q.S.; Rezende, J.L.P. \& Fernandes, G.W. 2000. Variations in leaf characteristics of two species of Miconia in the Brazilian cerrado under different light intensities. Tropical Ecology 41:47-60.

Martins, L.R.R.M.; Mourão, K.S.M.; Albiero, A.L.; Cortez, D.A.G.; Dias-Filho, B.P. \& Najamura, C.V. 2006. Estudo morfoanatômico preliminar do caule e da folha de Acanthospermum australe (Loefl.) Kuntze (Asteraceae -Heliantheae). Revista Brasileira de Farmacognosia 16: 42-52.

Mayer, J.L.S.; Alves, A.C.A.; Souza, L.A \& Bona, C. 2008. Morfo-anatomia da plântula e tirodendro de Rollinea sylvatica (A. St.-Hil.) Mart. (Annonaceae). Revista Brasileira de Botânica 31: 687-698.

Melo-de-Pinna, G.F.A. 2004. Anatomia foliar de Richterago Kuntze (Mutisieae, Asteraceae). Acta Botanica Brasilica 18: 591-600.

Metcalfe, C.R. \& Chalk, L. 1957. Anatomy of the dicotyledons: leaves, stem, and wood in taxonomy with notes on economics uses. Clarendon Press, Oxford. 1500p.

Monteiro, W.R.; Castro, M.M. \& Fahn, A. 1995. Observations on the development of foliar secretory cavities of Porophyllum lanceolatum (Asteraceae). Nordic Journal of Botany 15: 69-76. 
Monteiro, W.R.; Castro, M.M.; Mazzoni-Viveiros, S.C. \& Mahlberg, P.G. 2001. Development and some histochemical aspects of foliar glândulas trichomes of Stevia rebaudiana (Bert.) Bert. - Asteraceae. Revista Brasilileira de Botânica 24: 349-357.

O’Brien, T.P.; Feder, N. \& Mccully, M.E. 1964. Polychromatic staining of plant cell walls by toluidine blue O. Protoplasma 59: 368-373.

Ressel, K.; Guilherme, F.A.G.; Schiavini, I. \& Oliveira, P.E. 2004. Ecologia morfofuncional de plântulas de espécies arbóreas da Estação Ecológica de Panga, Uberlândia, Minas Gerais. Revista Brasileira de Botânica 27: 311-323.

Ricardi, M.; Torres, F.; Hernandez, C. \& Quinteiro, R. 1977. Morfologia de plántulas de árboles venezolanos, I. Revista Florestal Venezolana 27: 15-56.

Rossatto, D.R. \& Kolb, R.M. 2010. Gochnatia polymorpha (Less.) Cabrera (Asteraceae) changes in leaf structure due to differences in light and edaphic conditions. Acta Botanica Brasilica 24: 605-612.

Rotta, E. 2007. Manual de regeneração natural da floresta com Araucária. Série Técnica. Embrapa Florestas, Colombo. $4 \mathrm{p}$.

Santos, L.S.; Dariva, H.S.; Muller. R.H.; Almeida, O.J.G. \& Souza L.A. 2014. Seedling structure in Asteraceae weedy species: considerations on the vasculature system. Brazilian Journal of Botany 37: 631-635.
Sass, J.E. 1951. Botanical microtechnique. $2^{\text {nd }}$ ed. State College Press, Iowa. 228p.

Smith, G.L. 1982. Taxonomic considerations of Piptocarpha (Compositae: Vernonieae) and new taxa in Brazil. Brittonia 34: 210-218.

Solereder, H. 1908. Systematic anatomy of the dicotyledons. Clarendon Press, Oxford. 1182p.

Souza, L.A. 2009a. Anatomia da plântula e do tirodendro. In: Souza, L.A. (org.). Sementes e plântulas germinação, estrutura e adaptação. Todapalavra Editora, Ponta Grossa. Pp. 191-252.

Souza, L.A. 2009b. Morfologia e anatomia vegetal (célula, tecidos, órgãos e plântula). Editora Universidade Estadual de Ponta Grossa, Ponta Grossa. 258p.

Souza, L.A; Moscheta, I.S.; Mourão, K.S.M.; Albiero, A.L.M.; Montanher, D.R. \& Paoli, A.A.S. 2009. Morfologia da plântula e do tirodendro. In: Souza, L.A. (org.). Sementes e plântulas - germinação, estrutura e adaptação. Todapalavra Editora, Ponta Grossa. Pp. 119-190.

Souza, V.C. \& Lorenzi, H. 2008. Botânica sistemática: guia ilustrado para identificação das famílias de angiospermas da flora brasileira, baseado em APG II. Instituto Plantarum, Nova Odessa. 704p.

Turner, I.M. 1994. Sclerophylly: primarily protective? Funcional Ecology 8: 669-675.

Vogel, E.F. 1980. Seedlings of dicotyledons (structure, development, types). Pudoc/Centre for Agricultural Publishing and Documentation, Wageningen. 465p. 